\title{
A Review of Bowel Preparation Before Colorectal Surgery
}

\author{
Yeon Uk Ju, Byung Wook Min \\ Division of Colon and Rectal Surgery, Department of Surgery, Korea University Guro Hospital, Seoul, Korea
}

Infectious complications are the biggest problem during bowel surgery, and one of the approaches to minimize them is the bowel cleaning method. It was expected that bowel cleaning could facilitate bowel manipulation as well as prevent infectious complications and further reduce anastomotic leakage. In the past, with the development of antibiotics, bowel cleaning and oral antibiotics (OA) were used together. However, with the success of emergency surgery and Enhanced Recovery After Surgery, bowel cleaning was not routinely performed. Consequently, bowel cleaning using OA was gradually no longer used. Recently, there have been reports that only bowel cleaning is not helpful in reducing infectious complications such as surgical site infection (SSI) compared to OA and bowel cleaning. Accordingly, in order to reduce SSI, guidelines are changing the trend of only intestinal cleaning. However, a consistent regimen has not yet been established, and there is still controversy depending on the location of the lesion and the surgical method. Moreover, complications such as Clostridium difficile infection have not been clearly analyzed. In the present review, we considered the overall bowel preparation trends and identified the areas that require further research.

Keywords: Preoperative bowel preparation; Mechanical bowel preparation; Oral antibiotics; Surgical site infection; Colorectal surgery

\section{INTRODUCTION}

Infectious complications are a problem with bowel surgery, and one of the techniques that is constantly being studied to reduce them is bowel preparation. Preoperative bowel preparation traditionally refers to the removal of intestinal contents through mechanical cleaning with oral or rectal measures. The proposed benefits of using bowel preparations include reduced surgical site infection (SSI) rates, easier bowel manipulation during surgery, and reduced anastomotic leakage rates [1].

Since the 1980s, the successful results of emergency surgery without mechanical bowel preparation (MBP) have been linked to Enhanced Recovery After Surgery (ERAS). It has led surgeons to believe that MBP can be omitted. There have been many stud-

Received: Feb 28, 2020 - Revised: Mar 27, 2020 - Accepted: Apr 1, 2020 Correspondence to: Byung Wook Min, M.D.

Division of Colon and Rectal Surgery, Department of Surgery, Korea University Guro Hospital, 148 Gurodong-ro, Guro-gu, Seoul 08308, Korea Tel: +82-2-2626-3079, Fax: +82-2-2626-1148

E-mail: gsmin@korea.ac.kr

ORCID: https://orcid.org/0000-0002-3621-5113

(C) 2021 The Korean Society of Coloproctology

This is an open-access article distributed under the terms of the Creative Commons Attribution NonCommercial License (https://creativecommons.org/licenses/by-nc/4.0) which permits unrestricted noncommercial use, distribution, and reproduction in any medium, provided the original work is properly cited. ies on the necessity of MBP. The conclusions of these studies were that MBP itself did not provide any benefit with regards to infection after colon and rectal surgery. Therefore, the trend of surgery gradually flowed in the direction of not performing MBP due to ERAS [2-4]. Following this trend, MBP using oral antibiotics (OA) also decreased.

However, the importance of OA has not disappeared. An analysis of a nationwide database in the United States in the 2010s revealed that the use of OA with MBP reduced SSIs compared to MBP alone [5-7]. As the use of OA for the prevention of infection after colon and rectal surgery has been re-examined, several meta-analyses have shown that the use of OA with MBP reduces postoperative infection [8-10]. There have been recent changes in the clinical guidelines in various countries, and the combination of MBP and $\mathrm{OA}$ is recommended [11-13].

\section{HISTORY OF BOWEL PREPARATION}

Since the 1930s, infection and leakage from the anastomosis have been important risk factors in colorectal surgery; therefore, MBP was performed without clear evidence that it actually reduced complications [14]. Following the discovery of antibiotics, Poth $[15,16]$ conducted many experimental and clinical studies using poorly absorbed OA to reduce the concentration of bacteria in 
the lumen during or after mechanical preparation. MBP was required before the use of effective intestinal antimicrobial agents. It reduced the burden of intraluminal bacteria and supported the antimicrobial action of OA on the mucosal surface $[15,17]$.

Starting with sulfathalidine [18], various antibiotic therapies have been studied, such as neomycin alone or a combination of neomycin and tetracycline. However, tetracycline was prohibited due to the occurrence of resistance [19]. Instead of these drugs, the combination of kanamycin and MBP was recommended to prevent SSI [20].

Antibiotic therapy has unquestionably had a profound effect on the practice of surgery, but it created a widespread superstition among surgeons that antibiotics could prevent all infections. This led to the indiscriminate use of antibiotics for prevention in all patients, which raised concerns regarding some serious problems that abusing antibiotics could cause [21]. Moreover, the studies on antibiotics at that time were not prospective or randomized clinical studies, and the level of evidence in the studies was low. These studies focused only on determining the microbiological effects of each drug [22].

In 1972, Nichols et al. [23] introduced a protocol using neomycin and erythromycin with MBP, which reduced the SSI rate from $43 \%$ to $9 \%[24,25]$. This protocol proved that the combination of preoperative OA and MBP could synergistically decrease the intestinal bacterial load prior to surgery, thus reducing the contamination of the operative field $[12,26]$. Multiple trials from the 1970 s to the 1990s demonstrated the effectiveness of this approach. However, it was found that systemic antibiotics (SA) with MBP were more effective than OA with MBP [26].

However, in the 1990s, as economic pressure in the United States reduced preoperative hospitalization, quicker MBP became the order of the day. MBP was poor and required large volumes of polyethylene glycol solution to achieve the gastrointestinal motility effects of oral erythromycin, especially in the elderly. Due to poor compliance and poor preparation, antibiotics were not effectively delivered throughout the bowel. The benefits of OA and MBP disappeared. Therefore, there was an opinion that only systemic prophylactic antibiotics could be used instead of OA with MBP [14].

Several clinical trials were conducted to find the optimal SA. The results of these studies showed that the SSI rate did not decrease in the MBP group compared to the non-MBP group [2735]. Similarly, the results of meta-analyses demonstrated no benefit from MBP [36]. Therefore, MBP with antibiotics was largely abandoned because of concerns about the efficacy and safety of MBP [26].

Recently, there has been a general trend of reintroducing OA into preoperative MBP. Several surgical units have reported decreased SSIs after performing MBP combined with OA [37-39].

To better assess surgeon and hospital performance, the American College of Surgeons (ACS) National Surgical Quality Improvement Program (NSQIP) provides risk-adjusted results and models for comparison with goals that identify areas for improvement $[40,41]$. The ERAS Society has produced colorectal-related bundles to further standardize healthcare services based on evidence-based practices $[40,42,43]$. Many organizations have implemented various infection prevention bundles to reduce SSI, and numerous projects have been implemented nationwide to reduce preventable complications [38, 44-49]. Although these infection prevention measures have been emphasized, the protocol is inconsistent and the role and use of $\mathrm{OA}$ and $\mathrm{MBP}$ are still diverse.

\section{BOWEL PREPARATION IN THE PRESENT TIME}

\section{Mechanical bowel preparation vs. non-mechanical bowel preparation}

MBP for colon surgery aims to reduce stool mass and bacterial count to decrease the rate of SSI. Most studies reported no difference in infectious complications with and without MBP.

After Hughes [50] first questioned the effectiveness of MBP before colorectal surgery, several reports have emerged regarding the potential benefits of MBP. They have not consistently identified significant reduction or prevention of various infectious complications such as SSI, anastomotic leakage, and abdominal abscess $[3,36,51]$. Furthermore, according to some studies, MBP was not recommended during bowel surgery due to various side effects and discomfort in patients. There are not many reports on complications of MBP and patient acceptability, but individual studies have cited abdominal discomfort, bloating, fatigue, dehydration, nausea, and preoperative complications, as well as abnormal electrolyte imbalances and risk of perforation, especially in the elderly [32, 52-56]. In addition, relatively safe results have been reported in cases where MBP was not performed, such as in an emergency. Since then, colorectal surgery has been attempted without MBP before surgery [27, 36, 52, 56]. Zmora et al. [56] reported that intraluminal liquid content was a common finding in the MBP group and that intestinal content leakage occurred more frequently (liquid content: $37.4 \%$ vs. $13.5 \%, \mathrm{P}=0.0001$; Spillage of content: $16.6 \%$ vs. $9.3 \%, \mathrm{P}=0.046$ ). However, the postoperative infection rate did not differ between the 2 groups.

Bucher et al. [34] reported an increased risk of morbidity with MBP for selective left-sided colorectal surgery, and Santos et al. [57] reported an increased risk of wound infection due to MBP compared with no preparation ( $24 \%$ vs. $12 \%$ ), but no difference in the risk of anastomotic leakage.

Jung et al. [29] compared the MBP and non-MBP groups in 21 multicenter randomized clinical studies. In the 2 groups, the incidence of infectious complications was $7.9 \%$ and $6.8 \%$, the incidence of SSI was $15.1 \%$ and $16.1 \%$, and the anastomotic leakage rates were $2.3 \%$ and $2.6 \%$, respectively; and there was no statistical difference. Therefore, it was concluded that MBP was no longer necessary as it was judged not to reduce the incidence of complications in colorectal surgery. Similar results have been reported 
in other studies [27, 58].

Slim et al. [4] reported that non-MBP did not have a negative effect on SSI compared to MBP in a meta-analysis; however, anastomotic leakage was more common in patients who underwent MBP than in patients who did not $(5.6 \%$ vs. $3.2 \%$; odds ratio $[\mathrm{OR}], 1.74 ; 95 \%$ confidence interval $[\mathrm{CI}], 1.05-2.90 ; \mathrm{P}=0.032$ ). This suggests that leakage of bowel contents following inappropriate MBP is a risk factor for infectious complications. The incidence of infectious complications such as SSI and anastomotic leakage is rather high in patients undergoing MBP for the following reasons. First, MBP causes local changes in the large intestine, which prevent wound healing. And second, changes in fluid and electrolytes caused by intestinal cleaning affect wound healing [3].

The results of randomized control trials comparing MBP and non-MBP in colon surgery show that there is no benefit of MBP in all aspects of SSI and anastomotic leakage [37, 59]. The results of several studies on MBP are summarized in Table 1.

Until 2011, systematic reviews such as the Cochrane Review collected and published various data after review and meta-analysis, and there were continuous updates, and eventually, the implementation of MBP showed that there was no further advantage [3, $52,59]$. Therefore, several guidelines recommend that the implementation of MBP alone should be avoided to reduce SSI.

\section{Mechanical bowel preparation + oral antibiotics effect}

In a 1970s study comparing the effects of MBP and OA, it was reported that the SSI ratio in the MBP + OA group was smaller compared to that in the MBP alone group, but there was no confidence in the outcome [23]. However, in the early 1980s, it was reported that in the case of pretreatment using $\mathrm{MBP}$ and $\mathrm{OA}$, postoperative complications could be further reduced from $20 \%$ to $7 \%$ $[60,61]$. After these studies, the comparison between MBP and non-MBP in colorectal surgery was conducted by randomized and meta-analysis studies [52]. Table 2 summarizes the results of several studies on the effect of $\mathrm{MBP}+\mathrm{OA}$.

The Michigan Surgical Quality Collaborative made several reports, which consistently demonstrated the benefits of $\mathrm{MBP}+\mathrm{OA}$ in the reduction of SSIs [62-64]. They included OA bowel preparations as 1 of the 6 elements of the colon surgery bundle to prevent SSI [65].

Ohman et al. [40] compared the MBP + OA combined group with the MBP alone group in the analysis of the NSQIP and reported that patients who received $\mathrm{MBP}+\mathrm{OA}$ had an SSI rate of $2.7 \%$ compared with $15.8 \%$ for all others $(\mathrm{P}<0.001)$. $\mathrm{MBP}+\mathrm{OA}$ was reported to be the strongest independent factor (adjusted OR, $0.2 ; 95 \% \mathrm{CI}, 0.1-0.9 ; \mathrm{P}=0.006)$ influencing the reduction of SSI.

Koller et al. [66] classified patients into 4 groups (MBP, non$\mathrm{MBP}, \mathrm{OA}$ alone, and $\mathrm{MBP}+\mathrm{OA}$ ) in a retrospective study using the ACS NSQIP database of 32,359 people from 2012 to 2014, and compared the groups. The results were as follows; MBP was not associated with a reduction in the risk of SSI compared to the non-MBP group. Therefore, the use of MBP alone before regular

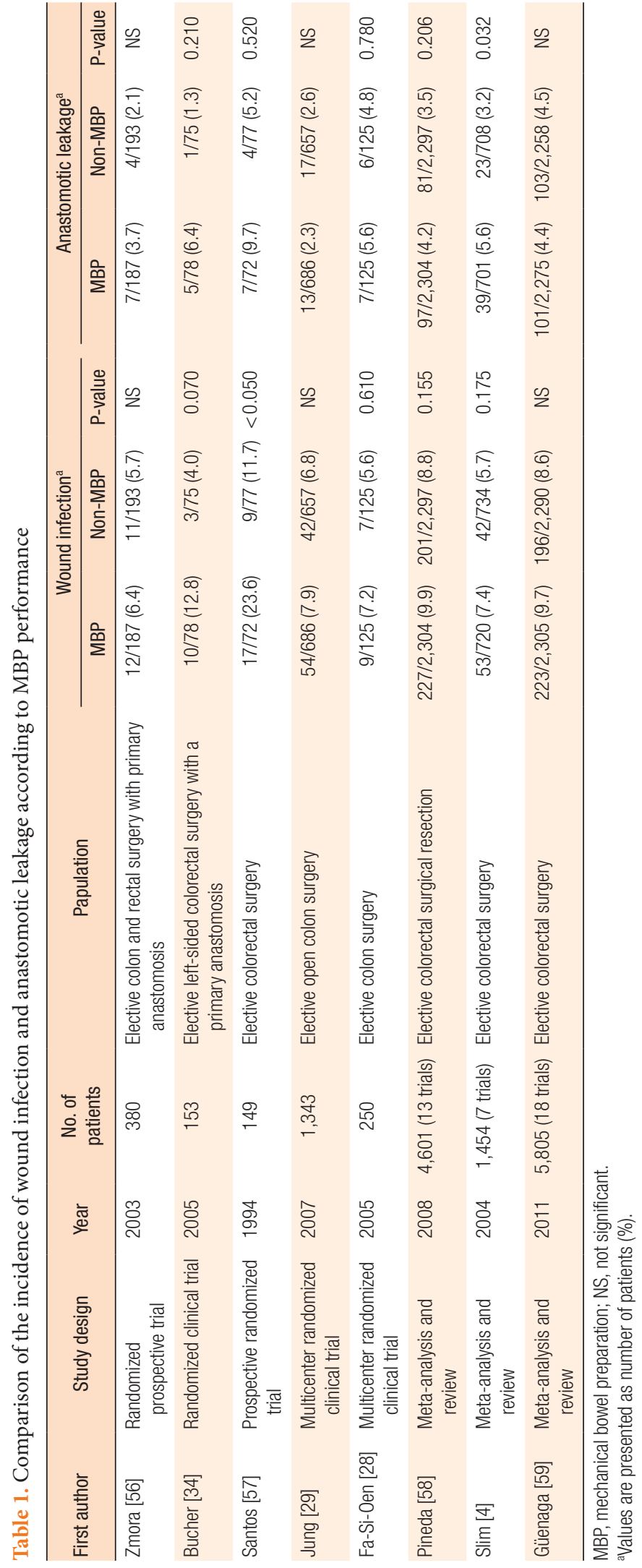




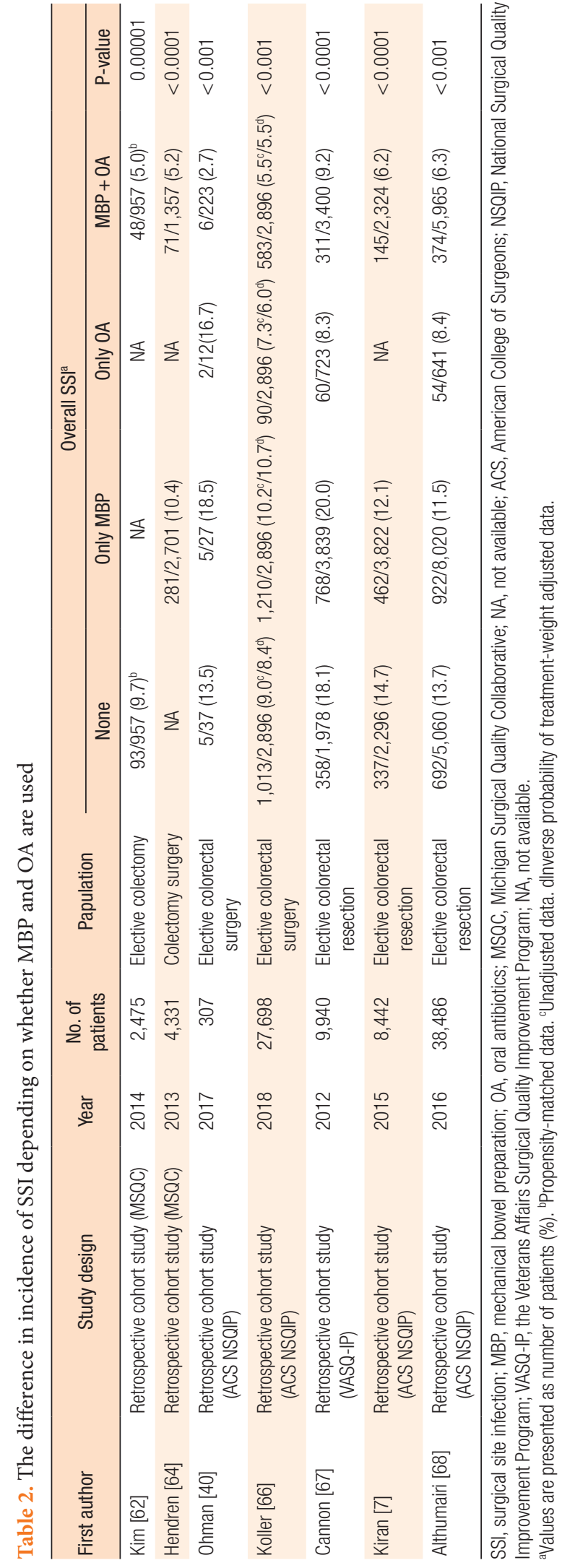

colon surgery is not effective in preventing SSI and is no longer recommended. In contrast, $\mathrm{OA}$ were associated with a reduced risk of all types of SSIs. The MBP + OA group had a significantly reduced risk of SSI and there was no increased risk of other complications compared to the MBP and non-MBP groups. In the multivariate analysis, the OR of the SSI frequency, anastomotic leakage rate, and mortality rate of $\mathrm{MBP}+\mathrm{OA}$ ranged between 0.43 and 0.57 , which is a very important result [52]. According to the study, although prospective studies are needed to determine the efficacy and risk of OA before colon surgery, MBP and OA should be used in combination before elective colon resection.

In a recent large-scale study in the United States, the combined use of MBP and OA was an independent factor in reducing the incidence of anastomotic leakage, SSI, and postoperative paralytic ileus when compared with the OA or MBP alone $[7,67,68]$. As a result, in 2019, in the American Society of Colon and Rectal Surgeons Clinical Practice guidelines [37], MBP combined with preoperative OA is typically recommended for elective colorectal resections (Grade of Recommendation: Strong recommendation based on moderate-quality evidence, $1 \mathrm{~B}$ ).

$\mathrm{MBP}+\mathrm{OA}$ was reflected in the World Health Organization guidelines. In addition, the ACS and Surgical Infections Society guidelines also recommend the combined use of MBP and OA. The recommended regimen of $\mathrm{OA}$ is not clear, but nonabsorbable antibiotics covering gram-negative and aerobic bacteria should be administered [12].

\section{Only oral antibiotics}

OA alone has been reported to reduce SSI [67]; however, it is not sufficient to improve all postoperative outcomes compared to $\mathrm{MBP}+\mathrm{OA}$.

In a 2016 randomized study comparing OA and OA + SA before colon surgery, Hata et al. [69] found that SSI decreased in patients receiving $\mathrm{OA}+\mathrm{SA}$ rather than $\mathrm{SA}$ alone $(7.3 \%$ vs. $12.8 \% ; \mathrm{P}=$ 0.028). Until clear research results are obtained, the combination of MBP and OA should be considered, rather than only OA.

\section{CURRENT ISSUES OF BOWEL PREPARATION}

\section{Rectal surgery}

In the case of anastomosis after rectal resection, there may be differences in the interpretation of the results because various methods such as MBP, non-MBP, and simple enema are used for preoperative bowel cleaning. Tables 3, 4 summarize the results of rectal surgery.

Bretagnol et al. [70] reported specifically on elective sphincterpreserving surgery for rectal cancer from the French Research Group of Rectal Cancer Surgery (GRECCAR) III randomized controlled trial. They demonstrated that rectal surgery without preoperative MBP was significantly associated with an increase in the 30-day overall morbidity and infectious complication rates (non-MBP vs. MBP: $44 \%$ vs. $27 \%, \mathrm{P}=0.018$ and $34 \%$ vs. $16 \%$, 


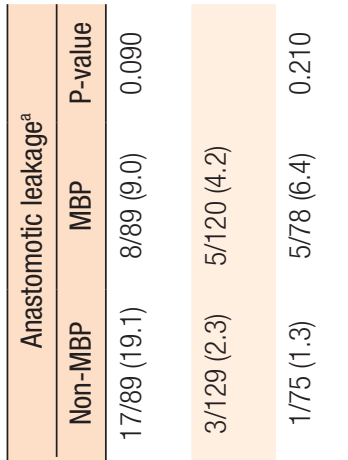

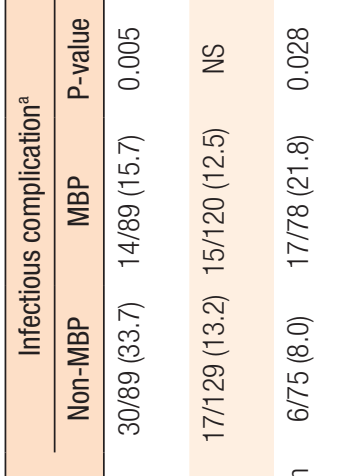

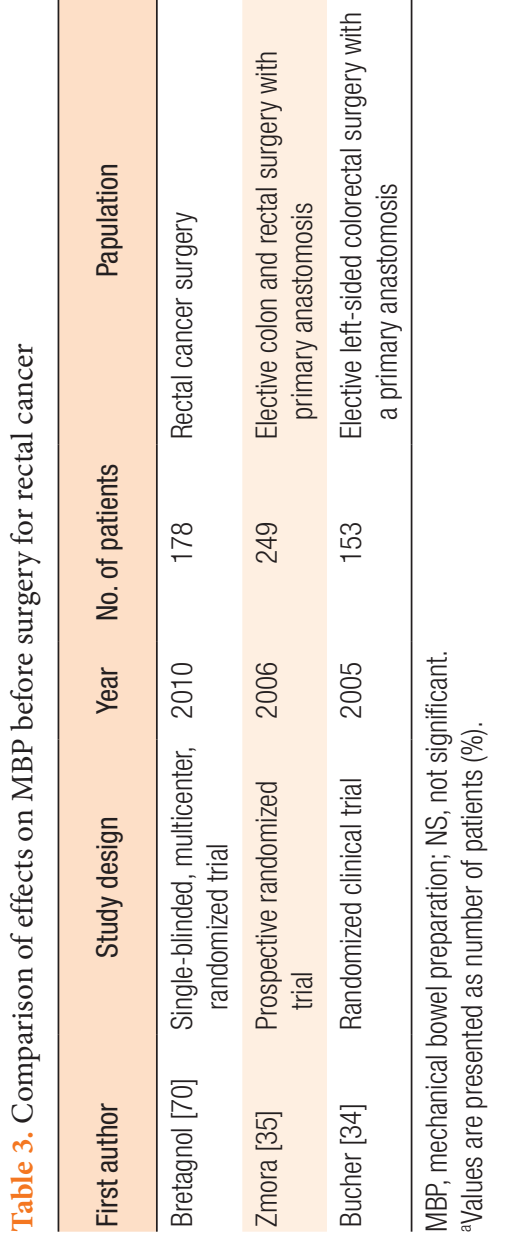

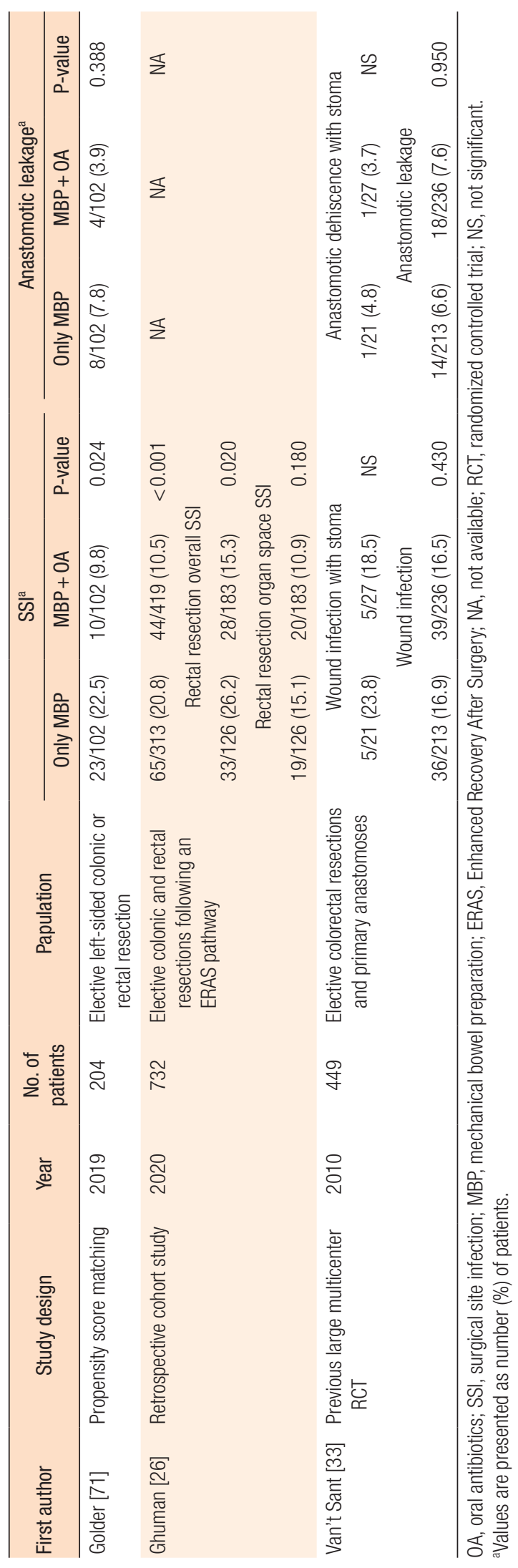


$\mathrm{P}=0.005$, respectively). In addition, there was a trend toward an increased risk of anastomotic leakage ( $19 \%$ vs. $10 \%, \mathrm{P}=0.09)$ and peritonitis ( $7 \%$ vs. $2 \%, \mathrm{P}=0.15)$, but the differences were not statistically significant [70].

Golder et al. [71] said that the use of preoperative OA + MBP + intravenous (IV) antibiotics for specific left bowel or rectal surgery can effectively reduce postoperative systemic inflammatory response and postoperative complications: overall complications (OR, 0.31; 95\% CI, $0.17-0.56 ; \mathrm{P}<0.001$ ), infective complications (OR, 0.41; 95\% CI, $0.22-0.77 ; \mathrm{P}=0.011$ ), and SSI (OR, 0.37; 95\% CI, $0.17-0.83 ; \mathrm{P}=0.024)$.

Ghuman et al. [26] reported a significant reduction in overall SSI rates $(26.2 \%$ vs. $15.3 \%, \mathrm{P}=0.02)$ and superficial SSI rates (11.1\% vs. $4.4 \%, \mathrm{P}=0.02)$, but not in organ space SSI rates $(15.1 \%$ vs. $10.9 \%, \mathrm{P}=0.18)$.

Zmora et al. [35] reported no difference in the rate of surgical infectious complications between the non-MBP and MBP groups. (13.2\% vs. 12.5\%). Similarly, Van't Sant et al. [33] reported that there was no significant difference between the MBP group and the non-MBP group in the occurrence of anastomotic leakage or septic complications (7.6\% vs. $6.6 \%)$. On the other hand, Bucher et al. [34] reported that the infectious complication rate was higher in the MBP group ( $22 \%$ vs. $8 \%, \mathrm{P}=0.028)$.

According to the Cochrane Review [59], there was no difference in the results of anastomotic leakage and SSI rates between MBP and non-MBP patients after low anterior resection. However, other studies have shown that the overall prevalence of infection was higher in the non-MBP group after elective surgery for rectal cancer $[51,52,71]$. There are very few randomized comparative studies between the MBP and non-MBP strategies related to rectal surgery.

In low rectal surgery, there is a variable called temporary diverting ileostomy, which is believed to reduce the incidence of anastomotic leakage, but this is still controversial [33]. Further research on $\mathrm{MBP}$ or enemas versus no preparation in patients undergoing elective rectal surgery is needed.

\section{Minimally invasive surgery}

Recently, laparoscopic surgery has become a primary surgical option for patients with colorectal cancer because of its several advantages over open surgery. There have been many randomized clinical trials on the benefits of MBP, but they are still unclear, especially for laparoscopic colorectal surgery [36]. In practice, the distended intestine interferes with the visual field during laparoscopic surgery and can make intestinal manipulation more difficult, so it is necessary to consider MBP [4].

Hata et al. [69] performed a multicenter randomized controlled trial to confirm the efficacy and regimen of oral and parenteral antibiotic prophylaxis in elective laparoscopic colon surgery. The incidence of SSIs in laparoscopic colorectal surgery remains high, at around $8 \%$ to $23 \%$. Although several guidelines have been published for antibiotic prophylaxis in cases of colorectal surgery, no

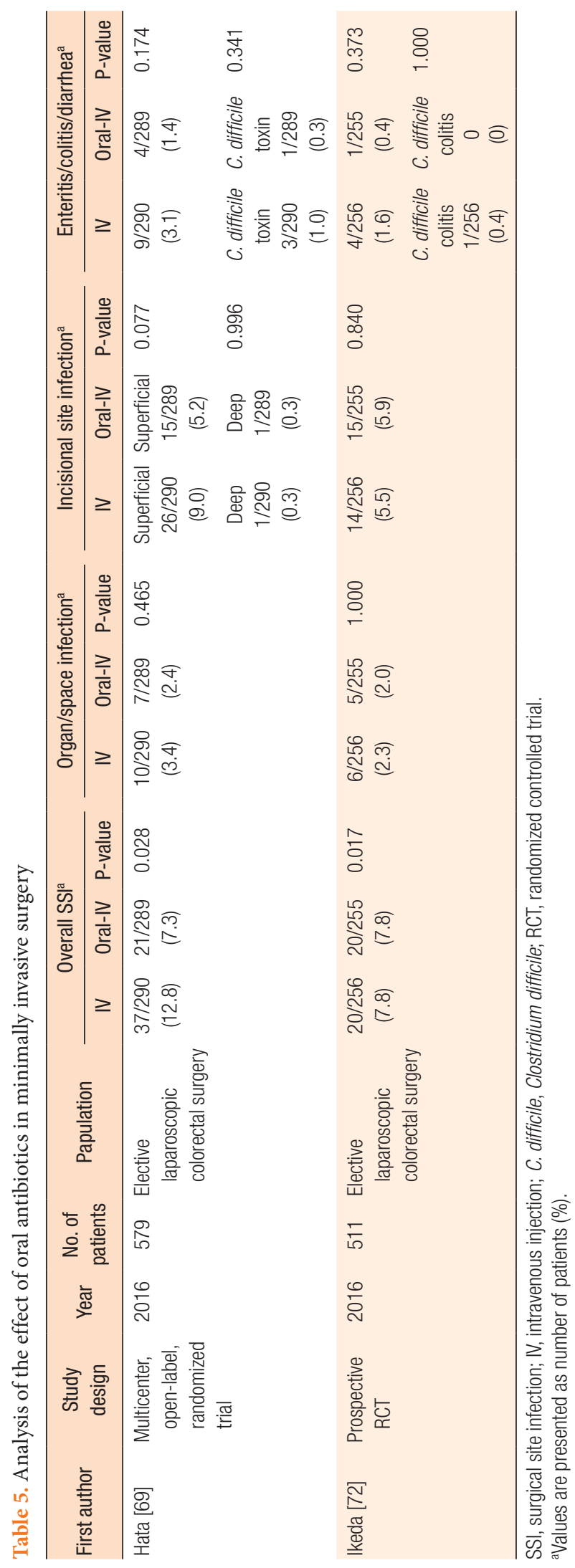


previous studies have determined the optimal antibiotic regimen for laparoscopic colorectal surgery. Oral and parenteral prophylaxis (oral, kanamycin and metronidazole; IV, cefmetazole) significantly reduced the incidence of SSIs in patients undergoing elective laparoscopic colorectal surgery without significantly increasing the incidence of enteritis/colitis/diarrhea and Clostridium difficile toxin in stool samples ( $7.26 \%$ vs. $12.8 \%$; OR, $0.536 ; 95 \% \mathrm{CI}$, $0.305-0.940 ; \mathrm{P}=0.028)$. Ikeda et al. [72] argued that with regard to SSI in patients with colorectal cancer undergoing elective laparoscopic resection, IV perioperative antimicrobial prophylaxis alone is not inferior to combined preoperative oral and IV prophylaxis (overall: $7.8 \%$ vs. $7.8 \%, \mathrm{P}=0.017$; incisional site: $5.5 \%$ vs. 5.9\%; organ/space infection: $2.3 \%$ vs. $2.0 \%$ ) (Table 5). Therefore, it is necessary to confirm whether $\mathrm{MBP}+\mathrm{OA}+\mathrm{IV}$ prophylaxis should be performed even in minimally invasive surgeries such as laparoscopic surgery.

\section{Clostridium difficile infection}

One of the concerns about the use of OA in patients undergoing colorectal surgery is C. difficile infection. Al-Mazrou et al. [73] conducted a study using ACS NSQIP data (2015 and 2016) on the incidence of OA-induced $C$. difficile infection in patients undergoing colon resection. They reported a $1 \%$ to $7 \%$ incidence of $C$. difficile infection after surgery; in the multivariate analysis, in the group that underwent preoperative OA and MBP, OA significantly lowered postoperative $C$. difficile infection (OR, 0.6; 95\% $\mathrm{CI}, 0.5-0.8)$. In patients without postoperative infectious complications, the use of OA has been reported to lower the incidence of C. difficile infection in all subgroups (OR, 0.7; 95\% CI, 0.5-0.9) $[52,73]$.

Kim et al. [62] collected data from the Michigan Surgical Quality Collaborative-Colectomy Best Practices Project and analyzed them by dividing them into groups of full bowel preparation (MBP with nonabsorbable OA) or no bowel preparation (neither MBP nor nonabsorbable OA administered). They report that patients receiving full preparation were less likely to develop postoperative C. difficile colitis ( $0.5 \%$ vs. $1.8 \%, \mathrm{P}=0.01)$.

Wren et al. [74] reported that the rate of postoperative C. difficile colitis was $4.2 \%$ in the entire study population. In this study, the rate of $C$. difficile infection was higher in patients who received $\mathrm{OA}$ than in those who did not ( $7.4 \%$ vs. $2.6 \%, \mathrm{P}=0.03$ ). The use of nonabsorbable $\mathrm{OA}$ in bowel preparation resulted in a higher rate of $C$. difficile infection.

The risk of $C$. difficile infection as a complication of OA bowel preparation is still not consistent.

\section{Antibiotic regimen}

Prophylactic antibiotics are needed to prevent infectious complications. However, uncontrolled analysis of the various routes, methods, and durations of administration remains problematic. Among the administration methods, only a few studies have been conducted on IV antibiotics, and preoperative intestinal cleaning methods are also diverse. The types and frequency of drugs used as prophylactic antibiotics, whether oral or IV, are also inconsistent. Therefore, it is difficult to draw a consistent conclusion [15].

Studies in the 1970s showed that oral kanamycin + erythromycin or neomycin + erythromycin was very effective in removing many intestinal pathogens associated with infection after surgery [7579]. Recently, as the necessity of bowel cleanliness has emerged again, studies using various antibiotic regimens have been conducted. Most studies used a combination of either ceftriaxone, cefoxitin, cefuroxime, flomoxef, cephazolin, amikacin with or without metronidazole with or without gentamicin, or ticarcillinclavulanate as the IV antibiotics of choice [80]. The most common OA therapy is neomycin + metronidazole, followed by kanamycin or neomycin with metronidazole, but microbiological evidence has not yet been established $[80,81]$. In some studies, gentamicin + metronidazole was administered as routine prophylaxis for 24 hours, 48 hours, or longer after surgery [8, 82]. Other studies included oral sulfamethoxazole/trimethoprim + metronidazole or doxycycline + metronidazole or oral neomycin + metronidazole within 24 hours before surgery, and IV administration ceftriaxone + metronidazole at induction $[8,31,52]$.

While many other poorly absorbed antibiotics are available, comparative studies of alternative drugs have been conducted in the last 20 years. However, the results of the analysis and evaluation of the timing of completion of OA prior to surgical intervention were not clearly obtained, and further studies are needed [14]. Therefore, the search for better mechanical and antibiotic preparation strategies should be reactivated.

\section{CONCLUSION}

To date, MBP has no effect on reducing SSI when used alone. It has been found to be effective only when used with OA. Therefore, various guidelines have been changed and $\mathrm{MBP}+\mathrm{OA}$ recommended. However, the results of the analysis of the surgical method, surgical site, and side effects of antibiotic use are not yet consistent, and the ideal antibiotic regimen has not yet been confirmed. Therefore, more research will have to be conducted to specify a clear method of cleaning the intestines.

\section{CONFLICT OF INTEREST}

No potential conflict of interest relevant to this article was reported.

\section{REFERENCES}

1. Diakosavvas M, Thomakos N, Psarris A, Fasoulakis Z, Theodora M, Haidopoulos D, et al. Preoperative bowel preparation in minimally invasive and vaginal gynecologic surgery. ScientificWorldJournal 2020;2020:8546037.

2. Platell C, Hall J. What is the role of mechanical bowel preparation 
in patients undergoing colorectal surgery? Dis Colon Rectum 1998;41:875-83.

3. Lewis J, Kinross J. Mechanical bowel preparation for elective colorectal surgery. Tech Coloproctol 2019;23:783-5.

4. Slim K, Vicaut E, Panis Y, Chipponi J. Meta-analysis of randomized clinical trials of colorectal surgery with or without mechanical bowel preparation. Br J Surg 2004;91:1125-30.

5. Scarborough JE, Mantyh CR, Sun Z, Migaly J. Combined mechanical and oral antibiotic bowel preparation reduces incisional surgical site infection and anastomotic leak rates after elective colorectal resection: an analysis of colectomy-targeted ACS NSQIP. Ann Surg 2015;262:331-7.

6. Garfinkle R, Abou-Khalil J, Morin N, Ghitulescu G, Vasilevsky $\mathrm{CA}$, Gordon $\mathrm{P}$, et al. Is there a role for oral antibiotic preparation alone before colorectal surgery?: ACS-NSQIP analysis by coarsened exact matching. Dis Colon Rectum 2017;60:729-37.

7. Kiran RP, Murray AC, Chiuzan C, Estrada D, Forde K. Combined preoperative mechanical bowel preparation with oral antibiotics significantly reduces surgical site infection, anastomotic leak, and ileus after colorectal surgery. Ann Surg 2015;262:416-25.

8. Bellows CF, Mills KT, Kelly TN, Gagliardi G. Combination of oral non-absorbable and intravenous antibiotics versus intravenous antibiotics alone in the prevention of surgical site infections after colorectal surgery: a meta-analysis of randomized controlled trials. Tech Coloproctol 2011;15:385-95.

9. Nelson RL, Gladman E, Barbateskovic M. Antimicrobial prophylaxis for colorectal surgery. Cochrane Database Syst Rev 2014;(5): CD001181.

10. Chen M, Song X, Chen LZ, Lin ZD, Zhang XL. Comparing mechanical bowel preparation with both oral and systemic antibiotics versus mechanical bowel preparation and systemic antibiotics alone for the prevention of surgical site infection after elective colorectal surgery: a meta-analysis of randomized controlled clinical trials. Dis Colon Rectum 2016;59:70-8.

11. Carmichael JC, Keller DS, Baldini G, Bordeianou L, Weiss E, Lee $\mathrm{L}$, et al. Clinical practice guidelines for enhanced recovery after colon and rectal surgery from the American Society of Colon and Rectal Surgeons and Society of American Gastrointestinal and Endoscopic Surgeons. Dis Colon Rectum 2017;60:761-84.

12. Allegranzi B, Bischoff P, de Jonge S, Kubilay NZ, Zayed B, Gomes $\mathrm{SM}$, et al. New WHO recommendations on preoperative measures for surgical site infection prevention: an evidence-based global perspective. Lancet Infect Dis 2016;16:e276-87.

13. Bratzler DW, Dellinger EP, Olsen KM, Perl TM, Auwaerter PG, Bolon MK, et al. Clinical practice guidelines for antimicrobial prophylaxis in surgery. Surg Infect (Larchmt) 2013;14:73-156.

14. Fry DE. Antimicrobial bowel preparation for elective colon surgery. Surg Infect (Larchmt) 2016;17:269-74.

15. Poth EJ. Historical development of intestinal antisepsis. World J Surg 1982;6:153-9.

16. Poth EJ. A clean intestinal anastomosis: an experimental study. Arch Surg 1934;28:1087-94.
17. Polk HC Jr. Contributions of alimentary tract surgery to modern infection control. Am J Surg 1987;153:2-8.

18. Poth EJ, Ross CA. The clinical use of phthalylsulfathiazole. J Lab Clin Med 1944;29:785-808.

19. Cohn I Jr, Longacre AB. Tetracycline (achromycin)-neomycin for preoperative colon preparation. AMA Arch Surg 1956;72:371-6.

20. Cohn I Jr. Kanamycin for bowel sterilization. Ann N Y Acad Sci 1958;76:212-23.

21. Altemeier WA, Culbertson WR, Veto M. Prophylactic antibiotic therapy. AMA Arch Surg 1955;71:2-6.

22. Fry DE. Colon preparation and surgical site infection. Am J Surg 2011;202:225-32.

23. Nichols RL, Condon RE, Gorbach SL, Nyhus LM. Efficacy of preoperative antimicrobial preparation of the bowel. Ann Surg 1972; 176:227-32.

24. Nichols RL, Smith JW, Garcia RY, Waterman RS, Holmes JW. Current practices of preoperative bowel preparation among North American colorectal surgeons. Clin Infect Dis 1997;24:609-19.

25. Klinger AL, Green H, Monlezun DJ, Beck D, Kann B, Vargas HD, et al. The role of bowel preparation in colorectal surgery: results of the 2012-2015 ACS-NSQIP data. Ann Surg 2019;269:671-7.

26. Ghuman A, Kasteel N, Brown CJ, Karimuddin AA, Raval MJ, Wexner SD, et al. Surgical site infection in elective colonic and rectal resections: effect of oral antibiotics and mechanical bowel preparation compared with mechanical bowel preparation only. Colorectal Dis 2020;22:1686-93.

27. Contant CM, Hop WC, van't Sant HP, Oostvogel HJ, Smeets HJ, Stassen LP, et al. Mechanical bowel preparation for elective colorectal surgery: a multicentre randomised trial. Lancet 2007; 370:2112-7.

28. Fa-Si-Oen P, Roumen R, Buitenweg J, van de Velde C, van Geldere $\mathrm{D}$, Putter $\mathrm{H}$, et al. Mechanical bowel preparation or not?: outcome of a multicenter, randomized trial in elective open colon surgery. Dis Colon Rectum 2005;48:1509-16.

29. Jung B, Påhlman L, Nyström PO, Nilsson E; Mechanical Bowel Preparation Study Group. Multicentre randomized clinical trial of mechanical bowel preparation in elective colonic resection. $\mathrm{Br}$ J Surg 2007;94:689-95.

30. Miettinen RP, Laitinen ST, Mäkelä JT, Pääkkönen ME. Bowel preparation with oral polyethylene glycol electrolyte solution vs. no preparation in elective open colorectal surgery: prospective, randomized study. Dis Colon Rectum 2000;43:669-77.

31. Pena-Soria MJ, Mayol JM, Anula R, Arbeo-Escolar A, FernandezRepresa JA. Single-blinded randomized trial of mechanical bowel preparation for colon surgery with primary intraperitoneal anastomosis. J Gastrointest Surg 2008;12:2103-9.

32. Perry WB. Is mechanical bowel preparation mandatory for elective colon surgery?: a prospective randomized study: commentary. Dis Colon Rectum 2007;50:129-30.

33. Van't Sant HP, Weidema WF, Hop WC, Oostvogel HJ, Contant $\mathrm{CM}$. The influence of mechanical bowel preparation in elective lower colorectal surgery. Ann Surg 2010;251:59-63. 
34. Bucher P, Gervaz P, Soravia C, Mermillod B, Erne M, Morel P. Randomized clinical trial of mechanical bowel preparation versus no preparation before elective left-sided colorectal surgery. $\mathrm{Br} J$ Surg 2005;92:409-14.

35. Zmora O, Mahajna A, Bar-Zakai B, Hershko D, Shabtai M, Krausz MM, et al. Is mechanical bowel preparation mandatory for left-sided colonic anastomosis?: results of a prospective randomized trial. Tech Coloproctol 2006;10:131-5.

36. Cao F, Li J, Li F. Mechanical bowel preparation for elective colorectal surgery: updated systematic review and meta-analysis. Int J Colorectal Dis 2012;27:803-10.

37. Migaly J, Bafford AC, Francone TD, Gaertner WB, Eskicioglu C, Bordeianou L, et al. The American Society of Colon and Rectal Surgeons Clinical Practice Guidelines for the use of bowel preparation in elective colon and rectal surgery. Dis Colon Rectum 2019;62:3-8.

38. Keenan JE, Speicher PJ, Thacker JK, Walter M, Kuchibhatla M, Mantyh CR. The preventive surgical site infection bundle in colorectal surgery: an effective approach to surgical site infection reduction and health care cost savings. JAMA Surg 2014;149: 1045-52.

39. Wick EC, Hobson DB, Bennett JL, Demski R, Maragakis L, Gearhart SL, et al. Implementation of a surgical comprehensive unitbased safety program to reduce surgical site infections. J Am Coll Surg 2012;215:193-200.

40. Ohman KA, Wan L, Guthrie T, Johnston B, Leinicke JA, Glasgow SC, et al. Combination of oral antibiotics and mechanical bowel preparation reduces surgical site infection in colorectal surgery. J Am Coll Surg 2017;225:465-71.

41. Ingraham AM, Richards KE, Hall BL, Ko CY. Quality improvement in surgery: the American College of Surgeons National Surgical Quality Improvement Program approach. Adv Surg 2010;44: 251-67.

42. Gustafsson UO, Scott MJ, Schwenk W, Demartines N, Roulin D, Francis N, et al. Guidelines for perioperative care in elective colonic surgery: Enhanced Recovery After Surgery (ERAS(R)) Society recommendations. World J Surg 2013;37:259-84.

43. Nygren J, Thacker J, Carli F, Fearon KC, Norderval S, Lobo DN, et al. Guidelines for perioperative care in elective rectal/pelvic surgery: Enhanced Recovery After Surgery (ERAS(R)) Society recommendations. World J Surg 2013;37:285-305.

44. Cima R, Dankbar E, Lovely J, Pendlimari R, Aronhalt K, Nehring $\mathrm{S}$, et al. Colorectal surgery surgical site infection reduction program: a national surgical quality improvement program--driven multidisciplinary single-institution experience. J Am Coll Surg 2013;216:23-33.

45. Wick EC, Galante DJ, Hobson DB, Benson AR, Lee KH, Berenholtz SM, et al. Organizational culture changes result in improvement in patient-centered outcomes: implementation of an integrated recovery pathway for surgical patients. J Am Coll Surg 2015;221:669-77.

46. Hedrick TL, Heckman JA, Smith RL, Sawyer RG, Friel CM, Foley
EF. Efficacy of protocol implementation on incidence of wound infection in colorectal operations. J Am Coll Surg 2007;205:4328.

47. Bull A, Wilson J, Worth LJ, Stuart RL, Gillespie E, Waxman B, et al. A bundle of care to reduce colorectal surgical infections: an Australian experience. J Hosp Infect 2011;78:297-301.

48. Keenan JE, Speicher PJ, Nussbaum DP, Adam MA, Miller TE, Mantyh CR, et al. Improving outcomes in colorectal surgery by sequential implementation of multiple standardized care programs. J Am Coll Surg 2015;221:404-14.

49. Lutfiyya W, Parsons D, Breen J. A colorectal "care bundle" to reduce surgical site infections in colorectal surgeries: a single-center experience. Perm J 2012;16:10-6.

50. Hughes ES. Asepsis in large-bowel surgery. Ann R Coll Surg Engl 1972;51:347-56.

51. Frontali A, Panis Y. Bowel preparation in colorectal surgery: back to the future? Updates Surg 2019;71:205-7.

52. Kim IY. Role of mechanical bowel preparation for elective colorectal surgery. Korean J Gastroenterol 2020;75:79-85.

53. Rollins KE, Javanmard-Emamghissi H, Lobo DN. Impact of mechanical bowel preparation in elective colorectal surgery: a metaanalysis. World J Gastroenterol 2018;24:519-36.

54. Eskicioglu C, Forbes SS, Fenech DS, McLeod RS; Best Practice in General Surgery Committee. Preoperative bowel preparation for patients undergoing elective colorectal surgery: a clinical practice guideline endorsed by the Canadian Society of Colon and Rectal Surgeons. Can J Surg 2010;53:385-95.

55. Slim K, Vicaut E, Launay-Savary MV, Contant C, Chipponi J. Updated systematic review and meta-analysis of randomized clinical trials on the role of mechanical bowel preparation before colorectal surgery. Ann Surg 2009;249:203-9.

56. Zmora O, Mahajna A, Bar-Zakai B, Rosin D, Hershko D, Shabtai $\mathrm{M}$, et al. Colon and rectal surgery without mechanical bowel preparation: a randomized prospective trial. Ann Surg 2003;237: 363-7.

57. Santos JC Jr, Batista J, Sirimarco MT, Guimarães AS, Levy CE. Prospective randomized trial of mechanical bowel preparation in patients undergoing elective colorectal surgery. Br J Surg 1994;81: 1673-6.

58. Pineda CE, Shelton AA, Hernandez-Boussard T, Morton JM, Welton ML. Mechanical bowel preparation in intestinal surgery: a meta-analysis and review of the literature. J Gastrointest Surg 2008;12:2037-44.

59. Güenaga KF, Matos D, Wille-Jørgensen P. Mechanical bowel preparation for elective colorectal surgery. Cochrane Database Syst Rev 2011;2011:CD001544.

60. Hares MM, Alexander-Williams J. The effect of bowel preparation on colonic surgery. World J Surg 1982;6:175-81.

61. Keighley MR, Arabi Y, Alexander-Williams J, Youngs D, Burdon DW. Comparison between systemic and oral antimicrobial prophylaxis in colorectal surgery. Lancet 1979;1:894-7.

62. Kim EK, Sheetz KH, Bonn J, DeRoo S, Lee C, Stein I, et al. A 
statewide colectomy experience: the role of full bowel preparation in preventing surgical site infection. Ann Surg 2014;259:310-4.

63. Krapohl GL, Phillips LR, Campbell DA Jr, Hendren S, Banerjee M, Metzger B, et al. Bowel preparation for colectomy and risk of Clostridium difficile infection. Dis Colon Rectum 2011;54:810-7.

64. Hendren S, Fritze D, Banerjee M, Kubus J, Cleary RK, Englesbe MJ, et al. Antibiotic choice is independently associated with risk of surgical site infection after colectomy: a population-based cohort study. Ann Surg 2013;257:469-75.

65. Waits SA, Fritze D, Banerjee M, Zhang W, Kubus J, Englesbe MJ, et al. Developing an argument for bundled interventions to reduce surgical site infection in colorectal surgery. Surgery 2014; 155:602-6.

66. Koller SE, Bauer KW, Egleston BL, Smith R, Philp MM, Ross HM, et al. Comparative effectiveness and risks of bowel preparation before elective colorectal surgery. Ann Surg 2018;267:734-42.

67. Cannon JA, Altom LK, Deierhoi RJ, Morris M, Richman JS, Vick $\mathrm{CC}$, et al. Preoperative oral antibiotics reduce surgical site infection following elective colorectal resections. Dis Colon Rectum 2012;55:1160-6.

68. Althumairi AA, Canner JK, Pawlik TM, Schneider E, Nagarajan N, Safar B, et al. Benefits of bowel preparation beyond surgical site infection: a retrospective study. Ann Surg 2016;264:1051-7.

69. Hata H, Yamaguchi T, Hasegawa S, Nomura A, Hida K, Nishitai R, et al. Oral and parenteral versus parenteral antibiotic prophylaxis in elective laparoscopic colorectal surgery (JMTO PREV 07-01): a phase 3, multicenter, open-label, randomized trial. Ann Surg 2016;263:1085-91.

70. Bretagnol F, Panis Y, Rullier E, Rouanet P, Berdah S, Dousset B, et al. Rectal cancer surgery with or without bowel preparation: the French GRECCAR III multicenter single-blinded randomized trial. Ann Surg 2010;252:863-8.

71. Golder AM, Steele CW, Conn D, MacKay GJ, McMillan DC, Horgan PG, et al. Effect of preoperative oral antibiotics in combination with mechanical bowel preparation on inflammatory response and short-term outcomes following left-sided colonic and rectal resections. BJS Open 2019;3:830-9.

72. Ikeda A, Konishi T, Ueno M, Fukunaga Y, Nagayama S, Fujimoto $\mathrm{Y}$, et al. Randomized clinical trial of oral and intravenous versus intravenous antibiotic prophylaxis for laparoscopic colorectal resection. Br J Surg 2016;103:1608-15.

73. Al-Mazrou AM, Hyde LZ, Suradkar K, Kiran RP. Effect of inclusion of oral antibiotics with mechanical bowel preparation on the risk of clostridium difficile infection after colectomy. J Gastrointest Surg 2018;22:1968-75.

74. Wren SM, Ahmed N, Jamal A, Safadi BY. Preoperative oral antibiotics in colorectal surgery increase the rate of Clostridium difficile colitis. Arch Surg 2005;140:752-6.

75. Washington JA 2nd, Dearing WH, Judd ES, Elveback LR. Effect of preoperative antibiotic regimen on development of infection after intestinal surgery: prospective, randomized, double-blind study. Ann Surg 1974;180:567-72.

76. Nichols RL, Broido P, Condon RE, Gorbach SL, Nyhus LM. Effect of preoperative neomycin-erythromycin intestinal preparation on the incidence of infectious complications following colon surgery. Ann Surg 1973;178:453-62.

77. Clarke JS, Condon RE, Bartlett JG, Gorbach SL, Nichols RL, Ochi S. Preoperative oral antibiotics reduce septic complications of colon operations: results of prospective, randomized, double-blind clinical study. Ann Surg 1977;186:251-9.

78. Matheson DM, Arabi Y, Baxter-Smith D, Alexander-Williams J, Keighley MR. Randomized multicentre trial of oral bowel preparation and antimicrobials for elective colorectal operations. Br J Surg 1978;65:597-600.

79. Wapnick S, Guinto R, Reizis I, LeVeen HH. Reduction of postoperative infection in elective colon surgery with preoperative administration of kanamycin and erythromycin. Surgery 1979;85: 317-21.

80. Toh JW, Phan K, Hitos K, Pathma-Nathan N, El-Khoury T, Richardson AJ, et al. Association of mechanical bowel preparation and oral antibiotics before elective colorectal surgery with surgical site infection: a network meta-analysis. JAMA Netw Open 2018;1: e183226.

81. Alverdy JC, Hyman N. Bowel preparation under siege. Br J Surg 2020;107:167-70.

82. Lewis RT. Oral versus systemic antibiotic prophylaxis in elective colon surgery: a randomized study and meta-analysis send a message from the 1990s. Can J Surg 2002;45:173-80. 